\title{
CASP-CUSUM Schemes Based on Truncated Dagum Distribution using Lobatto integration Method
}

\author{
Dr.B. Sainath ${ }^{1}$, Dr. P. Mohammed Akhtar ${ }^{2}$, G.Venkatesulu ${ }^{3}$ \\ And Dr. B.R. Narayana Murthy ${ }^{4}$ \\ Dept. of Statistics, Sri Krishanadevaraya University, Ananthapuramu-515003 \\ 4. Lecturer in Statistics Govt. (U.G\&P.G) College, Ananthapuramu-515001
}

\begin{abstract}
Acceptance sampling plans are introduced mainly to accept or reject the lots of finished products. There are several techniques available to control the quality. Some of the techniques are popularly used where testing involves destruction, for instance, in the manufacturing of crackers, bullets, batteries, bulbs and so on, it is impossible to go for $100 \%$ inspection. In this paper we optimized CASP-CUSUM Schemes based on the assumption that the continuous variable under consideration follows a Truncated Dagum Distribution. It is used the Lobatto Integration Method to solve the truncated integral equations. The Dagum Distribution is continuous distribution generally used in Life-time Analysis of products, particularly in estimating reliability by considering its distribution. Optimization of CASP-CUSUM Schemes is suggested based on numerical results obtained by changing the values of the parameters of the Dagum distribution.
\end{abstract}

Keywords: CASP-CUSUM Schemes, type-C, OC Curve, ARL, Truncated Dagum distribution.

\section{Introduction}

Procedures of statistical quality control are traditionally attributed to two main areas: acceptance sampling and statistical process control. The main aim of the oldest procedures of acceptance sampling, known as acceptance sampling plans, is to inspect certain items (products, documents, etc.) submitted for inspection in lots or batches. First acceptance sampling plans, proposed by one of the fathers of SQC, Harold Dodge, were designed for the inspection of lots submitted in sequences (lotby- lot inspection). The only aim of those plans, known as Dodge-Romig LTPD plans or Dodge-Romig AOQL plans, was to "screen" the inspected series of lots, and to reject lots of supposedly "spotty" quality. In case of stable production processes, i.e. processes characterized by constant probabilities of producing nonconforming items, high quality requirements can be achieved by occasional screening of rejected lots The concept of the acceptance sampling of lots submitted for inspection either in series or in isolation is typical of commercial activities of producers and consumers. Therefore, acceptance sampling plans, in contrast to control charts - the most popular tools of SPC - are mainly used for inspection of final products. This raises questions about their usefulness, as the real quality of a product is built-in during a production process. Therefore, one could ask a question about the possibility of using acceptance sampling procedures during the production process. The affirmative answer to this question was given by Harold Dodge (1943), who introduced continuous sampling plans. The idea behind these statistical procedures is exactly the same as in original acceptance sampling plans for lot-by-lot inspection, i.e. to "screen" production processes, but not only at their final stages. The same idea had motivated Wald and Wolfowitz (1945), who, at the same time, proposed other statistical procedures used for screening of continuous production processes. One of the most widely used qualities of control tools is the Acceptance Sampling Plans. Acceptance Sampling Plans determines the the "Sample Size" and Criteria for accepting or rejecting a product or batch based on the quality of a sample, using Statistical principles. Difference types of techniques are employed by industries mainly manufacturing of Bullets, Crackers, Bulbs, and Batteries and so on, where 100\% inspection is not possible. Sample provides one rational means of verification that a production lot conforms to the requirements of technical specifications. $100 \%$ inspection does not guarantee $100 \%$ compliance and is too time consuming an costly. Rather than evaluating all terms or products, a specified sample is taken, inspected or tested, and a decision is made about accepting or rejecting the entire production lot. Usually defer from time to time and also. In previous research the term "quality" defines in different dimensions, particularly with regards to consumer point of view, system designer's point of view etc. Particularly in consumer's point of view durability, safety, low-cost, the degree of satisfaction etc are the major characteristics which determine the quality of a product. Where as in producer's point of view the degree of profit and the degree of low cost of production are the major properties that determine the quality. The term quality is closely associated with reliability of the product. In most of the qualitative characteristics study, the quality of characteristics is related to many factors such as raw material used management, machinery and product life time. In order to study the quality of a product based on the product life time, many sampling procedures have been developed. It is very difficult to observe a highly reliable product within available experimental time duration. Therefore it is a 
common practice to truncate the experiment time during the implementation of sampling process, if no failure occurs within the experimental time period (or) the number of failures exceeds the specified number. The ordinary acceptance sampling plans for different distributions have been developed by many researcher including R.R.L. Kantam et al, N. Balakrishna et al. Generally, it requires more time, more cost, for supervision of each and every item produced. Therefore based on the sample information a decision of either acceptance or rejection of the lot is taken by adopting truncated probability failure distributions. Because, the ordinary acceptance sampling plan is usually expensive to implement. On the other hand, the experiment can be minimize the experimental cost by adopting acceptance sampling plans through the truncated probability failure distribution such as Exponential, Weibull, Half logistic Parato distribution and also it provides us more strict inspection of the product. Therefore the acceptance sampling plan has attracted to develop an acceptance sampling plan by using truncated Dagum probability distribution. The Dagum distribution is very flexible for modeling of life time of any product, and used for the life modeling in reliability analysis, life testing problems and acceptance sampling plans. The distribution has been experienced in many applications such as communication, engineering and life testing. For more details see D.D.Dyer and C.W.Whisenand and A.M. Polovko.

Therefore, in this chapter we proposed an acceptance sampling plan procedure under the assumption that the variable under study distributed according to truncated Dagum distribution. Under this assumption, we determine probability of accepting of lot $\mathrm{P}(\mathrm{A})$, Dra00wing a OC-Curve and ARL's function. Finally we compared the results at different values of the parameter.

Vardeman.S, Di-ou Ray [9] was introduced CUSUM control charts under the restriction that the values are regard to quality is exponentially distributed. Further the phenomena under study is the occurrence of rate of rare events and the inter arrival times for a homogenous poison process are identically independently distributed exponential random variables.

Kakoty. S., Chakravaborthy A.B. [5] proposed CASP-CUSUM charts under the assumption that the variable under study follows a Truncated Normal Distribution. Generally truncated distributions are employed in many practical phenomena where there is a constraint on the lower and upper limits of the variable under study. For example, in the production engineering items, the sorting procedure eliminates items above or bellows designated tolerance limits. It is worthwhile to note that any continuous variable be first approximated as an exponential variable.

Muhammed Riaz, Nasir Abbas and Ronald J.M.M Does [7] proposed two Runs rules schemes for the CUSUM Charts. The performance of the CUSUM and EWMA Charts are compared with the usual CUSUM and weighted CUSUM, the first initial response CUSUM compared with usual EWMA Schemes. This comparison stated that the proposed schemes perform better for small and moderate shifts.

Lonnie. C. Vance, [6] consider Average Run Length of cumulative Sum Control Charts for controlling for normal means and to determine the parameters of a CUSUM Chart.To determine the parameters of CUSUM Chart the acceptable and rejectable quality levels along with the desired respective ARL's are consider.

Hawkins, D. M. [3] proposed a fast accurate approximation for ARL's of a CUSUM Control Charts. This approximation can be used to evaluate the ARL's for Specific parameter values and the out of control ARL's of location and scale CUSUM Charts.

Mohammed Akhtar. P and Sarma K.L.A.P [1] proposed an optimization of CASP-CUSUM Schemes based on truncated two parametric Gamma distribution and evaluate L (0) L' (O) and probability of Acceptance and also Optimized CASP-CUSUM Schemes based numerical results. In this study, we proposed acceptance sampling method based on the truncated Dagum distribution under the assumption that the variable under study distributed according to truncated Dagum distribution under this assumption we determined an appropriate measures for CUSUM schemes by using Lobatto Method of Integration. Thus it is more worthwhile to study some interesting characteristics of this distribution. The characteristics and applications of the Dagum distribution were discussed The Dagum Distribution is a continuous probability distribution defined over all positive real numbers. It is named after Camilo Dagum, who proposed it in a series of papers in the 1970s.

A continuous random variable $\mathrm{X}$ assuming non-negative values is said to have Dagum Distribution with parameters $\mathrm{a}, \mathrm{b}, \mathrm{p}>0$, its probability density function is given by:

$$
f(x, a, b, p)=\frac{a p}{x}\left(\frac{\left(\frac{x}{b}\right)^{a p}}{\left(\left(\frac{x}{b}\right)^{a}+1\right)^{p+1}}\right)
$$

The random variable $\mathrm{X}$ is said to follow a truncated Dagum Distribution as: 


$$
f_{B}(x)=\frac{\frac{a p}{x}\left(\frac{\left(\frac{x}{b}\right)^{a p}}{\left(\left(\frac{x}{b}\right)^{a}+1\right)^{p+1}}\right)}{\left(1+\left(\frac{b}{B}\right)^{a}\right)^{-p}} \quad \mathrm{p}>0, \mathrm{a}>0, \mathrm{~b}>0
$$

where B is the truncated point of the Dagum Distribution

\section{Description Of The Plan And Type- C Oc Curve}

Battie [2] has suggested the method for constructing the continuous acceptance sampling plans. The procedure, suggested by him consists of a chosen decision interval namely, "Return interval" with the length h', above the decision line is taken. We plot on the chart the sum $S_{m}=\sum\left(X_{i}-k_{1}\right) X_{i}{ }^{\prime} s(i=1,2,3 \ldots \ldots .$.$) are$ distributed independently and $\mathrm{k}_{1}$ is the reference value. If the sum lies in the area of normal chart, the product is accepted and if it lies of the return chart, then the product is rejected, subject to the following assumptions.

1. When the recently plotted point on the chart touches the decision line, then the next point to be plotted at the maximum, i.e., $\mathrm{h}+\mathrm{h}$ '

2. When the decision line is reached or crossed from above, the next point on the chart is to be plotted from the baseline.

When the CUSUM falls in the return chart, network or a change of specification may be employed rather than outright rejection.

The procedure in brief is given below.

1. Start plotting the CUSUM at 0 .

2. The product is accepted when $S_{m}=\sum\left(X_{i}-k\right)<h$; when $\mathrm{S}_{\mathrm{m}}<0$, return cumulative to 0 .

3. When $h<S_{m}<h+h$ ' the product is rejected: when $S_{m}$ crossed h, i.e., when $S_{m}>h+h$ ' and continue rejecting product until $S_{m}>h+h$ ' return cumulative to $h+h$ '

The type-C, OC function, which is defined as the probability of acceptance of an item as function of incoming quality, when sampling rate is same in acceptance and rejection regions. Then the probability of acceptance $\mathrm{P}(\mathrm{A})$ is given by

$$
P(A)=\frac{L(0)}{L(0)+L^{\prime}(0)}
$$

Where L $(0)=$ Average Run Length in acceptance zone and

L' $(0)=$ Average Run Length in rejection zone.

Page E.S. [8] has introduced the formulae for L (0) and L' (0) as

$$
\begin{aligned}
L(0) & =\frac{N(0)}{1-P(0)} \\
L^{\prime}(0) & =\frac{N^{\prime}(0)}{1-P^{\prime}(0)}
\end{aligned}
$$

Where $\mathrm{P}(0)=$ Probability for the test starting from zero on the normal chart,

$\mathrm{N}(0)=\mathrm{ASN}$ for the test starting from zero on the normal chart,

$\mathrm{P}^{\prime}(0)=$ Probability for the test on the return chart and

$N^{\prime}(0)=$ ASN for the test on the return chart

He further obtained integral equations for the quantities

$\mathrm{P}(0), \mathrm{N}(0), \mathrm{P}^{\prime}(0), \mathrm{N}^{\prime}(0)$ as follows:

$$
P(z)=F\left(k_{1}-z\right)+\int_{0}^{h} P(y) f\left(y+k_{1}-z\right) d y,
$$




$$
\begin{aligned}
& N(z)=1+\int_{0}^{h} N(y) f\left(y+k_{1}-z\right) d y \\
& P^{\prime}(z)=\int_{k_{1}+z}^{B} f(y) d y+\int_{0}^{h} P^{\prime}(y) f\left(-y+k_{1}+z\right) d y \\
& N^{\prime}(z)=1+\int_{0}^{h} N^{\prime}(y) f\left(-y+k_{1}+z\right) d y \\
& F(x)=1+\int_{A}^{h} f(x) d x: \\
& F\left(k_{1}-z\right)=1+\int_{A}^{k_{1}-z} f(y) d y
\end{aligned}
$$

and $\mathrm{z}$ is the distance of the starting of the test in the normal chart from zero.

\section{METHOD OF SOLUTION}

We first express the integral equation (2.4) in the form

$$
F(X)=Q(X)+\int_{c}^{d} R(x, t) F(t) d t
$$

where

$$
\begin{aligned}
& F(X)=P(z), \\
& Q(X)=F(k-z), \\
& R(X, t)=f(y+k-z)
\end{aligned}
$$

Let the integral $I=\int_{c}^{d} f(x) d x$ be transformed to

$$
I=\frac{d-c}{2} \int_{c}^{d} f(y) d y=\frac{d-c}{2} \sum a_{i} f\left(t_{i}\right)
$$

Where $y=\frac{2 x-(c-d)}{d-c}$ where $\mathrm{a}_{\mathrm{i}}$ 's and $\mathrm{t}_{\mathrm{i}}$ 's respectively the weight factor and abscissa for the Gass-Chibyshev polynomial, given in Jain M.K. and et al [4] using (3.1) and (3.2), (2.4) can be written as

$$
F(X)=Q(X) \frac{d-c}{2} \sum a_{i} R\left(x, t_{i}\right) F\left(t_{i}\right)
$$

Since equation (3.3) should be valid for all values of $x$ in the interval (c, d), it must be true for $x=t_{i}, i=0(1) n$ then obtain.

$$
F\left(t_{i}\right)=Q\left(t_{i}\right)+\frac{d-c}{2} \sum a_{i} R\left(t_{j}, t_{i}\right) F\left(t_{i}\right) \quad j=0(1) n
$$

Substituting

$$
\begin{aligned}
& F\left(t_{i}\right)=F_{i}, Q\left(t_{i}\right)=Q_{i}, i=0(1) n, \text { in } \quad(3.4), \text { we get } \\
& \left.F_{0}=Q_{0}+\frac{d-c}{2}\left[a_{0} R\left(t_{0}, t_{0}\right) F_{0}+a_{1} R\left(t_{0}, t_{1}\right) F_{1}+\ldots \ldots \ldots . . a_{n} R\left(t_{0}, t_{n}\right) F_{n}\right)\right]
\end{aligned}
$$




$$
\begin{aligned}
& \left.F_{1}=Q_{1}+\frac{d-c}{2}\left[a_{0} R\left(t_{1}, t_{0}\right) F_{0}+a_{1} R\left(t_{1}, t_{1}\right) F_{1}+\ldots \ldots \ldots . . . a_{n} R\left(t_{1}, t_{n}\right) F_{n}\right)\right] \\
& \left.F_{n}=Q_{n}+\frac{d-c}{2}\left[a_{0} R\left(t_{n}, t_{0}\right) F_{0}+a_{1} R\left(t_{n}, t_{1}\right) F_{1}+\ldots \ldots \ldots . . . a_{n} R\left(t_{n}, t_{n}\right) F_{n}\right)\right]
\end{aligned}
$$

In the system of equations except $\mathrm{F}_{\mathrm{i}}, \mathrm{i}=0,1,2$. .n are known and hence can be solved for $F_{i}$, we solved the solved the system of equations by the method of Iteration.

For this we write the system (3.5) as

$\left.\left[1-T a_{0} R\left(t_{0}, t_{0}\right)\right] F_{0}=Q_{0}+T\left[a_{0} R\left(t_{0}, t_{0}\right) F_{0}+a_{1} R\left(t_{0}, t_{1}\right) F_{1}+\ldots \ldots \ldots a_{n} R\left(t_{0}, t_{n}\right) F_{n}\right)\right]$

$\left.\left[1-T a_{1} R\left(t_{1}, t_{1}\right)\right] F_{1}=Q_{1}+T\left[a_{0} R\left(t_{1}, t_{0}\right) F_{0}+a_{1} R\left(t_{1}, t_{1}\right) F_{1}+\ldots \ldots \ldots a_{n} R\left(t_{1}, t_{n}\right) F_{n}\right)\right]$

$\left.\left[1-T a_{n} R\left(t_{n}, t_{n}\right)\right] F_{n}=Q_{n}+T\left[a_{0} R\left(t_{n}, t_{0}\right) F_{0}+a_{1} R\left(t_{n}, t_{1}\right) F_{1}+\ldots \ldots \ldots a_{n} R\left(t_{n}, t_{n}\right) F_{n}\right)\right]$

Where $T=\frac{d-c}{2}$

To start the Iteration process, let us put $F_{1}=F_{2}=\ldots .=F_{n}=0$ in the first equation of (3.6), we then obtain a rough value of $F_{0}$. Putting this value of $F_{0}$ and $F_{1}=F_{2}=\ldots .=F_{n}=0$ on the second equation, we get the rough value $F_{1}$ and so on. This gives the first set of values $F_{i} \mathrm{i}=0,1,2, \ldots$, n which are just the refined values of $F_{i} \mathrm{i}=0,1,2, \ldots$, n. The process is continued until two consecutive until two consecutive sets of values are obtained up to a certain degree of accuracy. In the similar way solutions P' $(0), N(0), N^{\prime}(0)$ can be obtained.

\section{Computation Of Arl's P (A)}

We developed computer programs to solve these equations and we get the following results given in the Tables (4.1) to (4.17).

TABLE - 4.1

Values of ARL'S and Type-C OC Curves when

\begin{tabular}{|c|c|c|}
\hline B & $\mathrm{L}(0)$ & $\mathrm{L}^{\prime}(0)$ \\
\hline 2.7 & $2.46129 \quad 1.0145345$ & 0.7081165910 \\
\hline 2.6 & 2.685831 .0153438 & 0.7256695032 \\
\hline 2.5 & 3.002801 .0162773 & 0.7471364141 \\
\hline 2.4 & 3.481851 .0173618 & 0.7738801837 \\
\hline 2.3 & 4.285601 .0186311 & 0.8079586029 \\
\hline 2.2 & $5.90191 \quad 1.0201296$ & 0.8526257873 \\
\hline 2.1 & $10.77045 \quad 1.0219146$ & 0.9133409858 \\
\hline 2.0 & $818658.75000 \quad 1.0240631$ & 0.9999987483 \\
\hline
\end{tabular}
$\mathrm{a}=2 \mathrm{p}=2 \mathrm{~b}=2, k_{1}=2 \mathrm{~h}=.25 \mathrm{~h}^{\prime}=.25$

TABLE $-\mathbf{4 . 2}$

Values of ARL'S and Type-C OC Curves when $\mathrm{a}=2 \mathrm{p}=2 \mathrm{~b}=2, k_{1}=2 \quad \mathrm{~h}=.5 \quad \mathrm{~h}^{\prime}=.5$

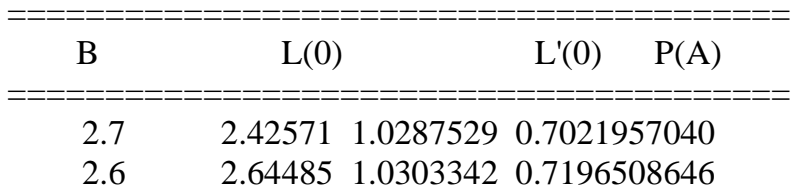




$\begin{array}{lrrrl}2.5 & 2.95421 & 1.0321556 & 0.7410785556 \\ 2.4 & 3.42178 & 1.0342675 & 0.7678959966 \\ 2.3 & 4.20629 & 1.0367345 & 0.8022638559 \\ 2.2 & 5.78395 & 1.0396391 & 0.8476405144 \\ 2.1 & 10.53620 & 1.0430893 & 0.9099177122 \\ 2.0 & 532750.06250 & 1.0472263 & 0.9999980330\end{array}$

TABLE - 4.3

Values of ARL'S and Type-C OC Curves when $\mathrm{a}=2 \mathrm{p}=2 \mathrm{~b}=2, k_{1}=2 \mathrm{~h}=.75 \quad \mathrm{~h}^{\prime}=.75$

\begin{tabular}{|c|c|c|}
\hline B & $\mathrm{L}(0)$ & $\mathrm{L}^{\prime}(0)$ \\
\hline \multicolumn{3}{|c|}{ 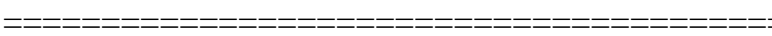 } \\
\hline 2.7 & 2.390831 .0426455 & 0.6963296533 \\
\hline 2.6 & 2.604731 .0449597 & 0.7136852145 \\
\hline 2.5 & $2.90670 \quad 1.0476205$ & 0.7350694537 \\
\hline 2.4 & 3.363131 .0506999 & 0.7619528770 \\
\hline 2.3 & 4.128971 .0542885 & 0.7965975404 \\
\hline 2.2 & 5.669201 .0585020 & 0.8426650763 \\
\hline 2.1 & $10.30883 \quad 1.0634894$ & 0.9064844251 \\
\hline 2.0 & $325092.15625 \quad 1.0694441$ & 10.9999967217 \\
\hline
\end{tabular}

TABLE -4.4

Values of ARL'S and Type-C OC Curves when $\mathrm{a}=2 \mathrm{p}=2 \quad \mathrm{~b}=2, k_{1}=2 \quad \mathrm{~h}=1 \quad \mathrm{~h}^{\prime}=1$

\begin{tabular}{|c|c|c|}
\hline B & $\mathrm{L}(0)$ & $\mathrm{P}(\mathrm{A})$ \\
\hline 2.7 & 2.356641 .0562019 & 0.6905213594 \\
\hline 2.6 & $2.56543 \quad 1.0592084$ & 0.7077758312 \\
\hline 2.5 & 2.860221 .0626587 & 0.7291128635 \\
\hline 2.4 & 3.305831 .0666429 & 0.7560552359 \\
\hline 2.3 & $4.05357 \quad 1.0712737$ & 0.7909647226 \\
\hline 2.2 & 5.557491 .0766935 & 0.8377051353 \\
\hline 2.1 & $\begin{array}{lll}10.08797 & 1.0830835\end{array}$ & 0.9030455351 \\
\hline 2.0 & $208742.81250 \quad 1.0906754$ & 40.9999947548 \\
\hline
\end{tabular}

TABLE - 4.5

Values of ARL'S and Type-C OC Curves when $\mathrm{a}=2 \mathrm{p}=2 \mathrm{~b}=2, k_{1}=4 \mathrm{~h}=.25 \quad \mathrm{~h}^{\prime}=.25$

\begin{tabular}{|c|c|c|}
\hline B & $\mathrm{L}(0)$ & $\mathrm{L}^{\prime}(0)$ \\
\hline \multicolumn{3}{|c|}{$==$} \\
\hline 4.7 & 9.246041 .0084912 & 0.9016540647 \\
\hline 4.6 & 10.417751 .0086052 & 0.9117299318 \\
\hline 4.5 & $\begin{array}{ll}12.06091 & 1.0087279\end{array}$ & 0.9228189588 \\
\hline 4.4 & $14.52927 \quad 1.0088599$ & 0.9350719452 \\
\hline 4.3 & $\begin{array}{ll}18.64821 & 1.0090023\end{array}$ & 0.9486701488 \\
\hline 4.2 & 26.893951 .0091562 & 0.9638335705 \\
\hline 4.1 & 51.647341 .0093230 & 0.9808319807 \\
\hline 4.0 & $5539248.50000 \quad 1.00950$ & 410.9999998212 \\
\hline
\end{tabular}

TABLE - 4.6

Values of ARL'S and Type-C OC Curves when $\mathrm{a}=2 \mathrm{p}=2 \mathrm{~b}=2, k_{1}=4 \quad \mathrm{~h}=.5 \quad \mathrm{~h}^{\prime}=.5$

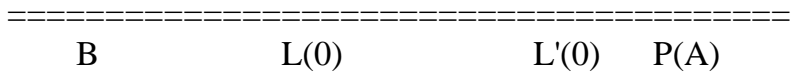




\begin{tabular}{|c|c|}
\hline 4.7 & $9.16778 \quad 1.01687720 .9001560211$ \\
\hline 4.6 & $\begin{array}{lll}10.32839 & 1.0171025 & 0.9103518724\end{array}$ \\
\hline 4.5 & $\begin{array}{lll}11.95600 & 1.0173445 & 0.9215819240\end{array}$ \\
\hline 4.4 & $\begin{array}{lll}14.40097 & 1.0176051 & 0.9340013266\end{array}$ \\
\hline 4.3 & $\begin{array}{llll}18.48090 & 1.0178860 & 0.9477974772\end{array}$ \\
\hline 4.2 & $26.64854 \quad 1.0181898 \quad 0.9631980658$ \\
\hline 4.1 & $\begin{array}{llll}51.16756 & 1.0185186 & 0.9804829359\end{array}$ \\
\hline 4.0 & $\begin{array}{llll}4115097.25000 & 1.0188757 & 0.9999997616\end{array}$ \\
\hline
\end{tabular}

TABLE -4.7

Values of ARL'S and Type-C OC Curves when $\mathrm{a}=2 \mathrm{p}=2 \mathrm{~b}=2, k_{1}=4 \mathrm{~h}=.75 \quad \mathrm{~h}^{\prime}=.75$

\begin{tabular}{|c|c|c|}
\hline B & $\mathrm{L}(0)$ & $\mathrm{L}^{\prime}(0)$ \\
\hline \multicolumn{3}{|c|}{ 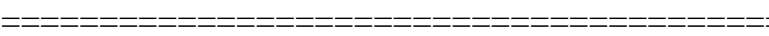 } \\
\hline 4.7 & 9.090451 .0251558 & 0.8986560702 \\
\hline 4.6 & $10.24011 \quad 1.0254893$ & 0.9089716077 \\
\hline 4.5 & $\begin{array}{lll}11.85235 & 1.0258477\end{array}$ & 0.9203422666 \\
\hline 4.4 & $14.27425 \quad 1.0262332$ & 0.9329280853 \\
\hline 4.3 & $\begin{array}{lll}18.31567 & 1.0266490\end{array}$ & 0.9469221234 \\
\hline 4.2 & $26.40622 \quad 1.0270981$ & 0.9625601768 \\
\hline 4.1 & $50.69381 \quad 1.0275844$ & 0.9801323414 \\
\hline 4.0 & $3261019.75000 \quad 1.028112$ & $\begin{array}{ll}3 & 0.9999997020\end{array}$ \\
\hline
\end{tabular}

TABLE - 4.8

Values of ARL'S and Type-C OC Curves when $\mathrm{a}=2 \mathrm{p}=2 \mathrm{~b}=2, k_{1}=4 \quad \mathrm{~h}=1 \quad \mathrm{~h}^{\prime}=1$

\begin{tabular}{|c|c|c|}
\hline B & $\mathrm{L}(0)$ & $\mathrm{L}^{\prime}(0)$ \\
\hline 4.7 & $9.01402 \quad 1.0333253$ & 0.8971543908 \\
\hline 4.6 & 10.152851 .0337639 & 0.9075892568 \\
\hline 4.5 & $\begin{array}{ll}11.74993 & 1.0342350\end{array}$ & 0.9191003442 \\
\hline 4.4 & $14.14905 \quad 1.0347420$ & 0.9318522215 \\
\hline 4.3 & $18.15248 \quad 1.0352885$ & 0.9460443258 \\
\hline 4.2 & $26.16695 \quad 1.0358787$ & 0.9619202018 \\
\hline 4.1 & $50.22596 \quad 1.0365175$ & 0.9797801971 \\
\hline 4.0 & 2307403.750001 .0372107 & 70.9999995232 \\
\hline
\end{tabular}

TABLE -4.9

Values of ARL'S and Type-C OC Curves when $\mathrm{a}=2 \mathrm{p}=2 \mathrm{~b}=2, k_{1}=6 \mathrm{~h}=.25 \mathrm{~h}^{\prime}=.25$

$===============================$
$\mathrm{B}$ $\begin{array}{cccc}\mathrm{L}(0) & \mathrm{L}(0) & \mathrm{P}(\mathrm{A}) \\ ============================= \\ 6.7 & 25.31567 & 1.0072268 & 0.9617357254 \\ 6.6 & 28.85059 & 1.0072628 & 0.9662647247 \\ 6.5 & 33.80325 & 1.0073005 & 0.9710633755 \\ 6.4 & 41.23680 & 1.0073401 & 0.9761543274 \\ 6.3 & 53.63263 & 1.0073818 & 0.9815632701 \\ 6.2 & 78.43432 & 1.0074255 & 0.9873186946 \\ 6.1 & 152.85904 & 1.0074717 & 0.9934523106 \\ \mathbf{6 . 0} & \mathbf{1 6 6 5 1 0 3 8 . 0 0 0 0 0} & \mathbf{1 . 0 0 7 5 2 0 2} & \mathbf{0 . 9 9 9 9 9 9 9 4 0 4} \\ ===================================\end{array}$


TABLE - 4.10

Values of ARL'S and Type-C OC Curves when $\mathrm{a}=3 \mathrm{p}=3 \mathrm{~b}=3, k_{1}=2 \quad \mathrm{~h}=.25 \quad \mathrm{~h}^{\prime}=.25$

\begin{tabular}{|c|c|c|}
\hline B & $\mathrm{L}(0)$ & $\mathrm{L}^{\prime}(0)$ \\
\hline & & \\
\hline 2.7 & 1.189651 .0000947 & 0.5432827473 \\
\hline 2.6 & 1.242121 .0001158 & 0.5539646745 \\
\hline 2.5 & 1.320261 .0001441 & 0.5689778328 \\
\hline 2.4 & $1.44447 \quad 1.0001827$ & 0.5908685327 \\
\hline 2.3 & $\begin{array}{ll}1.66261 & 1.0002367\end{array}$ & 0.6243729591 \\
\hline 2.2 & 2.118661 .0003138 & 0.6792811751 \\
\hline 2.1 & 3.533181 .0004262 & 0.7793312669 \\
\hline 2.0 & 299813.031251 .000594 & $\begin{array}{ll}6 & 0.9999966621\end{array}$ \\
\hline
\end{tabular}

TABLE - 4.11

Values of ARL'S and Type-C OC Curves when $\mathrm{a}=3 \mathrm{p}=3 \mathrm{~b}=3, k_{1}=2 \quad \mathrm{~h}=.5 \quad \mathrm{~h}^{\prime}=.5$

\begin{tabular}{|c|c|c|c|}
\hline B & $\mathrm{L}(0)$ & & $\mathrm{L}^{\prime}(0)$ \\
\hline 3.0 & 1.10578 & 1.0001136 & 0.5250880718 \\
\hline 2.9 & 1.12594 & 1.0001328 & 0.5295875669 \\
\hline 2.8 & 1.15286 & 1.0001574 & 0.5354615450 \\
\hline 2.7 & 1.18979 & 1.0001894 & 0.5432882309 \\
\hline 2.6 & 1.24230 & 1.0002316 & 0.5539713502 \\
\hline 2.5 & 1.32049 & 1.0002882 & 0.5689860582 \\
\hline 2.4 & 1.44479 & 1.0003656 & 0.5908787847 \\
\hline 2.3 & 1.66309 & 1.0004737 & 0.6243858337 \\
\hline
\end{tabular}

TABLE - 4.12

Values of ARL'S and Type-C OC Curves when $\mathrm{a}=3 \mathrm{p}=3 \mathrm{~b}=3, k_{1}=2 \mathrm{~h}=.75 \quad \mathrm{~h}^{\prime}=.75$

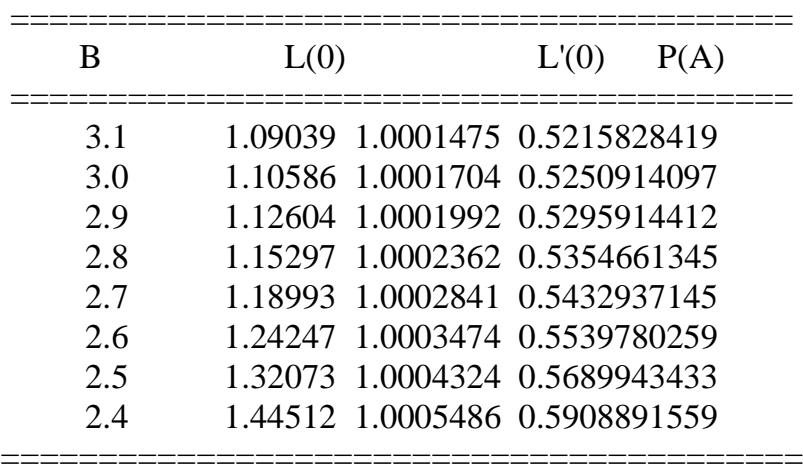

TABLE - 4.13

Values of ARL'S and Type-C OC Curves when $\mathrm{a}=3 \mathrm{p}=3 \mathrm{~b}=3, k_{1}=4 \quad \mathrm{~h}=.25 \quad \mathrm{~h}^{\prime}=.25$

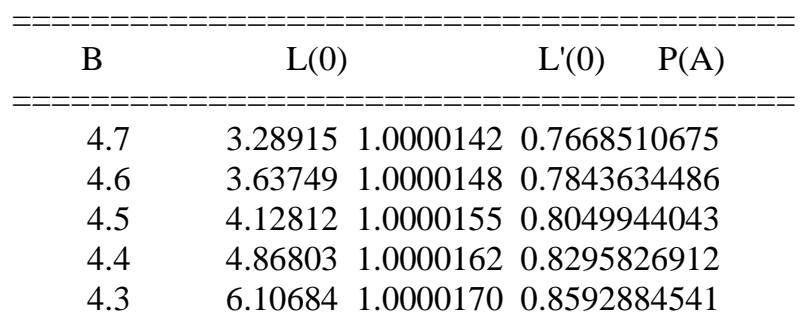


$4.2 \quad 8.59352 \quad 1.0000180 \quad 0.8957612514$

$4.1 \quad 16.07290 \quad 1.0000191 \quad 0.9414265752$

$\begin{array}{lllll}4.0 & 1525239.87500 & 1.0000204 & 0.9999993443\end{array}$

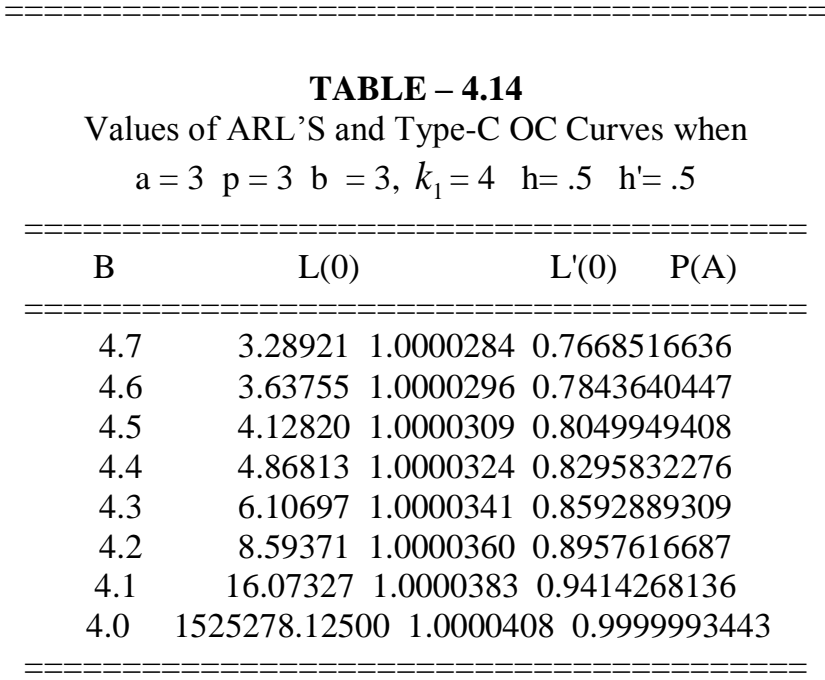

TABLE - 4.15

Values of ARL'S and Type-C OC Curves when $\mathrm{a}=3 \mathrm{p}=3 \mathrm{~b}=3, k_{1}=6 \mathrm{~h}=.25 \quad \mathrm{~h}^{\prime}=.25$

$==============================$
$\mathrm{B}$ $\begin{array}{cccc}\mathrm{L}(0) & \mathrm{L}(0) & \mathrm{P}(\mathrm{A}) \\ & =========================== \\ 6.7 & 10.98537 & 1.0000092 & 0.9165642262 \\ 6.6 & 12.40314 & 1.0000093 & 0.9253900051 \\ 6.5 & 14.39213 & 1.0000094 & 0.9350311756 \\ 6.4 & 17.38090 & 1.0000095 & 0.9455952048 \\ 6.3 & 22.36947 & 1.0000097 & 0.9572087526 \\ 6.2 & 32.35779 & 1.0000098 & 0.9700217247 \\ 6.1 & 62.34573 & 1.0000099 & 0.9842134714 \\ 6.0 & 5592475.50000 & 1.0000101 & 0.9999998212 \\ ================================\end{array}$

\section{TABLE - 4.16}

Values of ARL'S and Type-C OC Curves when $\mathrm{a}=3 \mathrm{p}=3 \mathrm{~b}=3, k_{1}=6 \quad \mathrm{~h}=.5 \quad \mathrm{~h}^{\prime}=.5$

$==============================$
$\mathrm{B}$ $\begin{array}{cccc}\mathrm{L}(0) & \mathrm{L}(0) & \mathrm{P}(\mathrm{A}) \\ & ========================== \\ 6.7 & 10.98549 & 1.0000184 & 0.9165644050 \\ 6.6 & 12.40328 & 1.0000186 & 0.9253901243 \\ 6.5 & 14.39230 & 1.0000188 & 0.9350312948 \\ 6.4 & 17.38110 & 1.0000191 & 0.9455953240 \\ 6.3 & 22.36974 & 1.0000193 & 0.9572088122 \\ 6.2 & 32.35818 & 1.0000196 & 0.9700217843 \\ 6.1 & 62.34649 & 1.0000199 & 0.9842134714 \\ 6.0 & 5592544.50000 & 1.0000203 & 0.9999998212 \\ =================================\end{array}$

TABLE -4.17

Values of ARL'S and Type-C OC Curves when $\mathrm{a}=3 \mathrm{p}=3 \mathrm{~b}=3, k_{1}=6 \mathrm{~h}=.75 \quad \mathrm{~h}^{\prime}=.75$

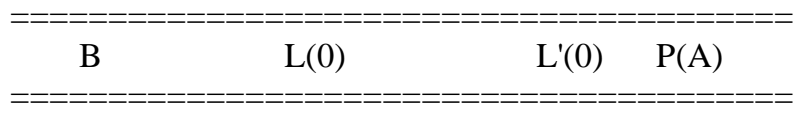




$\begin{array}{crrrr}6.7 & 10.98562 & 1.0000275 & 0.9165645838 \\ 6.6 & & 12.40343 & 1.0000279 & 0.9253903031 \\ 6.5 & 14.39246 & 1.0000283 & 0.9350314140 \\ 6.4 & 17.38130 & 1.0000286 & 0.9455954432 \\ 6.3 & 22.37000 & 1.0000290 & 0.9572089314 \\ 6.2 & 32.35857 & 1.0000293 & 0.9700218439 \\ 6.1 & 62.34726 & 1.0000298 & 0.9842135310 \\ 6.0 & 5592614.50000 & 1.0000303 & 0.9999998212 \\ ===============================\end{array}$

\section{V. $\quad$ Numerical Results And Conclusions}

At the hypothetical values of the parameters a,p,b, $k_{1}, h$ and $h$ ' given at the top of each table, we determine optimum truncated point $\mathrm{B}$ at which $\mathrm{P}(\mathrm{A})$ the probability of accepting an item is maximum and also obtained ARL's values which represents the acceptance zone $\mathrm{L}(0)$ and rejection zone L' $(0)$ values. The values of truncated point B of random variable X, L(0), L'(0) and the values for Type-C Curve, i.e. P (A) are given in columns I, II, III, and IV respectively.

From the above tables (4.1) to (4.17) we made the following conclusions

1. From the table (4.1) to (4.4), it was observed that the value of L (0) and P (A) are increase as the value of truncated point decreases thus the truncated point of the random variable and the various parameters for CASP-CUSUM are related.

2. And also we observed that it can be minimize the truncated point B by increasing value of $k_{1}$

3. From table (4.1) to (4.4), it is observed that truncated point B of the random variable $\mathrm{X}$ decrease from 2.7 to 2.0 as $\mathrm{h} \rightarrow 1.0$, while the value of $\mathrm{L}(0)$ decrease from 818658.75 to 208742.8125 and rejection zone values changes from 1.0240631 to 1.0906754 where as the probability of acceptance P (A) changes from 0.9999987483 to 0.9999947548 thus hypothetical value $\mathrm{h}$ and truncated point B inversely related, while the values $\mathrm{L}(0), \mathrm{L}$ ' $(0)$ and $\mathrm{P}(\mathrm{A})$ are positively related.

4. From table (4.5) to (4.8), it is observed that at the maximum level of probability of acceptance P (A) the truncated point $\mathrm{B}$ from 4.7 to 4.0 as the value of $\mathrm{h}$ changes from 0.25 to 1.0 .

5. From table (4.5) to (4.8), it is observed that the size of acceptance zone is changes from 5539248.5 to 2307403.75 thus the optimal truncated point and size of the acceptance zone are positively related.

6. From the table (4.9), it was observed that the truncated point B changes from 6.7 to 6.0 and $\mathrm{P}$ (A) is as

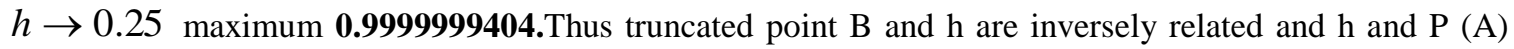
are positively related.

7. From the table (4.10) to (4.12), it was observed that the value of L (0) and P (A) are increase as the value of truncated point decreases thus the truncated point of the random variable and the various parameters for CASP-CUSUM are related.

8. From table (4.13) to (4.14), it is observed that at the maximum level of probability of acceptance P (A) the truncated point $B$ from 4.7 to 4.0 as the value of $h$ changes from 0.25 to 0.50

9. From table (4.13) to (4.14), it is observed that the size of acceptance zone is changes from 1525239.875 to 1525278 thus the optimal truncated point and size of the acceptance zone are positively related.

10. From table 4.15 to 4.17 , it is observed that at the maximum level of probability of acceptance $\mathrm{P}$ (A) the truncated point $B$ from 6.7 to 6.0 as the value of $h$ changes from 0.25 to 0.75

11. The various relations exhibited among the ARL's and Type-C OC Curves with the parameters of the CASPCUSUM based on the above table (4.1) to (4.17) are observed from the following Table (5.1).

Table 5.1

\begin{tabular}{|l|l|l|l|l|l|l|l|l|l|}
\hline $\mathrm{B}$ & $\mathrm{a}$ & $\mathrm{p}$ & $\mathrm{b}$ & $k_{1}$ & & $h^{\prime}$ & $L(O)$ & $L^{\prime}(O)$ & $P(A)$ \\
\hline 2.0 & 2 & 2 & 2 & 2 & 0.25 & 0.25 & 818658.7500 & 1.0240631 & 0.9999987483 \\
\hline 2.0 & 2 & 2 & 2 & 2 & 0.5 & 0.5 & 532750.06250 & 1.0472263 & 0.9999980330 \\
\hline 2.0 & 2 & 2 & 2 & 2 & 0.75 & 0.75 & 325092.15625 & 1.0694441 & 0.9999967217 \\
\hline 2.0 & 2 & 2 & 2 & 2 & 1.0 & 1.0 & 208742.81250 & 1.0906754 & 0.9999947548 \\
\hline 4.0 & 2 & 2 & 2 & 4 & 0.25 & 0.25 & 5539248.5000 & 1.0095041 & 0.9999998212 \\
\hline 4.0 & 2 & 2 & 2 & 4 & 0.5 & 0.5 & 4115097.2500 & 1.0188757 & 0.9999997616 \\
\hline 4.0 & 2 & 2 & 2 & 4 & 0.75 & 0.75 & 3261019.7500 & 1.0281123 & 0.9999997020 \\
\hline 4.0 & 2 & 2 & 2 & 4 & 1.0 & 1.0 & 2307403.7500 & 1.0372107 & 0.9999995232 \\
\hline
\end{tabular}




\begin{tabular}{|l|l|l|l|l|l|l|l|l|l|}
\hline $\mathbf{6 . 0}$ & $\mathbf{2}$ & $\mathbf{2}$ & $\mathbf{2}$ & $\mathbf{6}$ & $\mathbf{0 . 2 5}$ & $\mathbf{0 . 2 5}$ & $\mathbf{1 6 6 5 1 0 3 8 . 0 0 0}$ & $\mathbf{1 . 0 0 7 5 2 0 2}$ & $\mathbf{0 . 9 9 9 9 9 9 9 4 0 4}$ \\
\hline 2.0 & 3 & 3 & 3 & 2 & 0.25 & 0.25 & 299813.03125 & 1.0005946 & 0.9999966621 \\
\hline 2.3 & 3 & 3 & 3 & 2 & 0.5 & 0.5 & 1.66309 & 1.0004737 & 0.6243858337 \\
\hline 2.4 & 3 & 3 & 3 & 2 & 0.75 & 0.75 & 1.44512 & 1.0005486 & 0.5908891559 \\
\hline 4.0 & 3 & 3 & 3 & 4 & 0.25 & 0.25 & 1525239.8750 & 1.0000204 & 0.9999993443 \\
\hline 4.0 & 3 & 3 & 3 & 4 & 0.5 & 0.5 & 1525278.1250 & 1.0000408 & 0.9999993443 \\
\hline 6.0 & 3 & 3 & 3 & 6 & 0.25 & 0.25 & 5592457.500 & 1.0000101 & 0.9999998212 \\
\hline 6.0 & 3 & 3 & 3 & 6 & 0.5 & 0.5 & 5592544.500 & 1.0000203 & 0.9999998212 \\
\hline 6.0 & 3 & 3 & 3 & 6 & 0.75 & 0.75 & 5592614.500 & 1.0000303 & 0.9999998212 \\
\hline
\end{tabular}

By observing the Table 5.1, we can conclude that the optimum CASP-CUSUM Schemes which have the values of $\mathrm{ARL}$ and $\mathrm{P}(\mathrm{A})$ reach their maximum i.e., 16651038.00, $\mathbf{0 . 9 9 9 9 9 9 9 4 0 4}$ respectively, is

$$
\left[\begin{array}{l}
B=6.0 \\
a=2 \\
p=2 \\
b=2 \\
k_{1}=6 \\
h=0.25 \\
h^{\prime}=0.25
\end{array}\right]
$$

On similar lines we can obtain CASP-CUSUM Schemes when a particular parameter is fixed at a point, for example, if we fixed the value of $k_{1}=2$ in that case only the maximum value of probability of acceptance $\mathrm{P}(\mathrm{A})=0.9999987483$, is

$$
\left[\begin{array}{l}
B=2.0 \\
a=2 \\
p=2 \\
b=2 \\
k_{1}=2 \\
h=0.25 \\
h^{\prime}=0.25
\end{array}\right]
$$

\section{REFERENCES}

[1] Akhtar, P. Md. and Sarma, K.L.A.P. (2004). "Optimization of CASP-CUSUM Schemes based on Truncated Gamma Distribution”. Bulletin of Pure and applied sciences, Vol-23E (No.2):215-223.

[2] Beattie, B.W.(1962). "A Continuous Acceptance Sampling procedure based upon a cumulative Sums Chart for number of defective". Applied Statistics, Vol. $11 \quad$ (No.2): 137-147.

[3] Hawkins, D.M. (1992). "A Fast Accurate Approximation for Average Lengths of CUSUM Control Charts". Journal on Quality Technology, Vol. 24(No.1): 37-43.

[4] Jain, M.K. ,Iyengar, S.R.K. and Jain, R.K. "Numerical Methods of Scientific and Engineering Computations", Willy Eastern Ltd., New Delhi.

[5] Kakoty, S and Chakravaborthy, A.B., (1990), "A Continuous Acceptance Sampling Plan for Truncated Normal distribution based on Cumulative Sums", Journal of National Institution for Quality and Reliability, Vol.2 (No.1): 15-18

[6] Lonnie, C. Vance. (1986). "Average Run Length of CUSUM Charts for Controlling Normal means". Journal of Quality Technology, Vol.18:189-193.

[7] Muhammad Riaz, Nasir, Abbas and and Ronald, J.M.M. Does, (2011). "Improving the performance of CUSUM charts", Quality and Reliability Engineering International, Vol.27:415-424.

[8] Page, E.S.,(1954) “Continuous Inspection Schemes”, Biometrika, Vol. XLI, pp. 104-114.

[9] Vardeman, S. and Di-ou Ray. (1985). "Average Run Lenghts for CUSUM schemes where observations are Exponentially Distributed”, Technometrics, vol. 27 (No.2): 145-150. 
[10] Narayana Muthy, B. R, Akhtar, P. Md and Venkataramudu, B.(2012) "Optimization of CASP-CUSUM Schemes based on Truncated Log-Logistic Distribution”. Bulletin of Pure and applied Sciences, Vol-31E (Math\&Stat.): Issue (No.2) pp243-255.

[11] Narayana Muthy, B. R, Akhtar, P. Md and Venkataramudu, B. (2013) "Optimization of CASP-CUSUM Schemes based on Truncated Rayleigh Distribution". International Journal of Engineering and Development, Volum 6, Issue 2, pp. 37-44

[12] B.Sainath, P.Mohammed Akhtar, G.Venkatesulu, and Narayana Muthy, B. R, (2016) "CASP-CUSUM Schemes based on Truncated Burr Distribution using Lobatto Integration Method". IOSR Journal of Mathematics (IOSR-JM), Vol-12, Issue 2 pp.54-63. 